\title{
FACTORS IMPEDING THE ADOPTION OF WEED MANAGEMENT PRACTICES IN FOUR CROPPING SYSTEMS OF THE PUNJAB, PAKISTAN
}

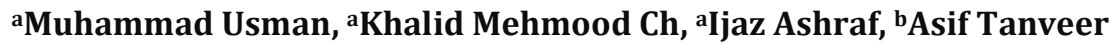 \\ ${ }^{a}$ Institute of Agricultural Extension, Education and Rural Development, University of Agriculture Faisalabad, Pakistan. \\ ${ }^{b}$ Department of Agronomy, University of Agriculture Faisalabad, Pakistan.
}

ART ICLE INF O

\section{Article History}

Received: January 18, 2020

Revised: March 12, 2020

Accepted: April 27, 2020

\section{Keywords}

Weeds

Information

Knowledge

Yield loss

Resources

Cropping systems
A B S T RACT

This study was conducted in district Gujranwala with the major objective to identify factors impeding the awareness level and adoption of weed management practices among the farmers from Rice-Wheat, Rice-Potato, Rice-Maize and Rice-Peas cropping systems. Total 356 farmers, selected through the proportionate sampling technique from four cropping systems participated in the study. Data were collected through a structured and validated questionnaire through a face-to-face interview technique and analyzed with the help of Statistical Package for Social Sciences (SPSS). Findings indicated that, inadequate resources, knowledge and limited exposure to the information sources were the factors influencing the awareness level among farmers across the four cropping systems Shortage of finance, high cost of inputs, high cost of diesel and possession of inadequate knowledge were the barriers impeding adoption level. This study suggests that, in order to create awareness and foster the adoption of recommended weed management technologies to further curb the yield losses, the Extension Field Staff should strive to build technical knowledge among farmers through diversified teaching activities. The Integration of Information Communication Technologies (ICTs) could help EFS to meet farmers information needs. Furthermore, public-private partnership is also recommended especially for the effective weeds' management on farm level.

Corresponding Author: Muhammad Usman

Email:malikusmanuaf@gmail.com

(C) The Author(s) 2021.

\section{INTRODUCTION}

Weed infestation is a critical issue that farmers confront with, because the weeds compete for nutrients uptake and surface area cover, and reducing yield significantly. Owing to a lack of information about weed varieties, management methods, and farmers' inability to take effective weed control steps, weed control had become tedious. Without effective control over weeds, yield losses cannot be reduced (Chamanabad, 2011; Smith et al., 2015). Weeds are hosts for many invasive insects and pests likely to pose further damage on plants and reducing yield by up to $15-20 \%$, if not properly controlled (Rubiales et al., 2009). In Pakistan, weeds are one of the main causes for crop yield reduction. If, weeds are not controlled in their first forty days, yield can drop from 40 to $50 \%$ (Oad et al., 2007). Weed infestation can reduce the yield by $20-40 \%$ in wheat crop, $20-63 \%$ in rice, $20-55 \%$ in cotton, $10-18 \%$ in potatoes and up to $45 \%$ of yield reduction in corn by using the various land inputs in the form of water and substances nutrients through the root areas (Maqbool et al., 2006). Weeds are important biotic factors which fight with plants for nutrients, escalate production cost, boos losses and reduce the quality and yield eventually. Thus, controlling 
weeds is indispensable to achieve potential crop yield deems necessary for food sufficiency. Oerke (2005) arbitrated a $13.2 \%$ decrease to food and crop production due to weeds. Weed infestation in any cereal crop depends on the time of emergence, species and location. Globally, the pre-emergence weeds are regarded more harmful as compared to post emergence.

With reference to inadequate control of weeds, crop yield losses are higher than the caused by pathogenic viruses (bacteria and fungi), birds, rodents and nematodes (Oerke, 2005). Major crop yield losses caused by different weed species for rice, wheat and maize were found as 15-66, 10-60, and 18-65\%, respectively (Rao et al., 2015; Jabran and Chauhan, 2015).

Weeds are controlled culturally, biologically and through chemicals. Cultural control is perceived expensive, laborious and time consuming but still effective. Cultural practices, such as recommended seed rates, irrigation strategies, resistant varieties, and nutrient management had positive as well as negative effects on weeds infestation (Chauhan and Opeña, 2013). Mechanical approaches minimize growers' dependence on chemicals, give effective control against resistance weeds and reduce the amount of weed seeds present in the soil (Vencill et al., 2012). Interaction between weeds and crops in order to achieve better yield is indeed complex. The capacity of a specific crop depends on the morphological and physiological factors that allow any crop to use nutrients, water, light and other limited resources that have a positive or negative effect on weed growth. All these situations depend significantly on the culture, system and the crop model (Norsworthy et al., 2012). Chemical control of weeds through herbicides is most despite of its disadvantages on environment. Herbicides are effective in controlling weeds by virtue of saving time, easy access and removing labor costs (Chauhan, 2012) but the high cost of herbicides, inadequate awareness about their safe use and environmental pollution being caused due to overuse of herbicides (Borlaug, 2002). Weeds are also controlled biologically serving as a natural solution in organic agriculture (Cook, 1988). This control method is not augmented best to control a large number of weeds (Muller et al., 2000). Biological control has no disadvantages on the crop and environment (Kropff and Walter, 2000). In rural settings of Pakistan, farmers utilize number of techniques under the Integrated Weeds Management (IWM) umbrella to get control over weeds. farmers use cultural measures (manual mixing, crop rotation, burning and grazing), chemical control (use of herbicides), biological method (use of allelopathy and predator), mechanical measures (plough or plantations) and protection measures (use of clean seeds and tools, clean tillage machines, water channel cleaning) (Riaz et al., 2006).

Farmers are provided with the necessary technical support in order to control weeds by the extension advisory services providers. This is indeed true that timely dissemination of information packages to farmers plays an important role in increasing production and adopting much necessary techniques (Cartmell et al., 2004). Different educational procedures are used to train and enable famers to improve their agricultural practices, techniques; increase production and income; improving living standards and raising social, economic and educational standards. Decisions on weed control programs are relatively subjective and are based on many characteristics of farmers which include their specific lifestyles, beliefs, goals and perceptions. Thus, most agricultural technologies have failed due to many factors where one of the important one is the lack of involvement of local farmers and minimal attention to their experiences, practices, desires and needs (Prudent et al., 2007). Therefore, it was regarded obligatory to examine the awareness and adoption among farmers regarding different weed management practices. The study was focused on following objectives;

- To explore the demographic attributes of the farmers

- To assess the factors affecting awareness level of the farmers regarding weeds of different cropping systems

- To assess the factors affecting adoption of recommended weeds management techniques in different cropping systems

\section{METHODOLOGY}

This study was conducted in District Gujranwala of the Punjab province of Pakistan. The Gujranwala district is famous for its potential regarding agriculture and four types of cropping systems such as rice-wheat, riceberseem, rice-maize, rice-potato. The study district has a total of five tehsils (Sub-districts) including Gujranwala city, Gujranwala Sadar, Wazirabad, Kamuke and Nowshera Virkan. Taking the resources into an account, this study was further narrowed to three sub-districts 
Wazirabad, Kamuke and Nowshera Virkan, that were selected purposively for having larger number of farmers. Proportionate sampling technique was used for the sample selection. The list of farmers was obtained from the office of the Deputy Director of Agriculture (Extension), Gujranwala. The obtained list contained 4782 farmers practicing crop farming under different cropping systems.

Of the total farmers in the list, 1645 farmers were from rice-wheat cropping system, 1360 from rice-maize, 935 from rice-potato and 842 from rice-peas cropping system. The online software www.surveysystem.com was used to generate the sample size taking 4782 farmers as the known population for the study at $95 \%$ confidence level and confidence interval of 5\%. Through proportionate sampling technique, 122 from rice-wheat, 101 from rice-maize, 70 from rice-potato and 63 respondents from rice-peas cropping system were selected thereby making a total sample size of 356 respondents.

Structured questionnaire was administered through face-to-face interview technique for data collection. The likert scale for this study in order to measure the level of awareness and adoption was used as1 = very low, $2=$ low, 3 = medium, 4 = high, 5 = very high. Statistical
Package for Social Sciences (SPSS) was used for the analysis of collected data.

\section{RESULTS AND DISCUSSION}

This section reflects the meaningful interpretation of the data collected and analyzed. This section is further divided into following sections such as (i) socioeconomic characteristics of the respondents (ii) factors creating awareness level of farmers about weeds management practices (iii) factors affecting adoption regarding weed management practices in different cropping such as rice-wheat (R-W), rice-potato (R-P), rice-maize (R-M) and rice-peas (R-Peas).

\section{Demographic profile of the respondents}

The demographic profile of respondents included age, education, annual income, farm size, tenancy status, sources of income, household size and farming experience. Socio-economic attributes of the farmers had close association with the awareness level of farmers and the adoption of respective agricultural technologies (Ashraf et al., 2015). Fadare et al. (2014) maintained that the socio-economic attributes of participating farmers had great influence on farmers behavioral developments towards adoption (Table 1).

Table 1. Demographic profile of respondents.

\begin{tabular}{|c|c|c|c|c|c|c|c|c|c|c|}
\hline \multirow[t]{2}{*}{ Attributes } & \multicolumn{2}{|c|}{ Rice Wheat } & \multicolumn{2}{|c|}{ Rice-Potato } & \multicolumn{2}{|c|}{ Rice Maize } & \multicolumn{2}{|c|}{ Rice-Pease } & \multicolumn{2}{|c|}{ Total } \\
\hline & $\mathrm{F}$ & $\%$ & $\mathrm{~F}$ & $\%$ & $\mathrm{~F}$ & $\%$ & $\mathrm{~F}$ & $\%$ & $\mathrm{~F}$ & $\%$ \\
\hline \multicolumn{11}{|c|}{ Age } \\
\hline Young & 32 & 26.2 & 19 & 27.1 & 25 & 24.8 & 28 & 44.4 & 104 & 29.2 \\
\hline Middle & 53 & 43.4 & 36 & 51.4 & 40 & 39.6 & 17 & 27.0 & 146 & 41.0 \\
\hline Old & 37 & 30.3 & 15 & 21.4 & 36 & 35.6 & 18 & 28.6 & 106 & 29.8 \\
\hline \multicolumn{11}{|c|}{ Education } \\
\hline Illiterate & 23 & 18.9 & 17 & 24.3 & 25 & 24.8 & 14 & 22.2 & 79 & 22.2 \\
\hline Primary-Middle & 57 & 46.7 & 27 & 38.6 & 38 & 37.6 & 15 & 23.8 & 137 & 38.5 \\
\hline Matric & 25 & 20.5 & 19 & 27.1 & 33 & 32.7 & 15 & 23.8 & 92 & 25.8 \\
\hline Above Matric & 17 & 13.9 & 7 & 10.0 & 5 & 5.0 & 19 & 30.2 & 48 & 13.5 \\
\hline \multicolumn{11}{|c|}{ Household size } \\
\hline Up to 5 & 42 & 34.4 & 29 & 41.4 & 36 & 35.6 & 24 & 38.1 & 131 & 36.8 \\
\hline $6-10$ & 50 & 41.0 & 26 & 37.1 & 42 & 41.6 & 20 & 31.7 & 138 & 38.8 \\
\hline Above 10 & 30 & 24.6 & 15 & 21.4 & 23 & 22.8 & 19 & 30.2 & 87 & 24.4 \\
\hline \multicolumn{11}{|c|}{ Tenancy Status } \\
\hline Owner & 81 & 66.4 & 46 & 65.7 & 72 & 71.3 & 32 & 50.8 & 231 & 64.9 \\
\hline Owner-cum-tenant & 37 & 30.3 & 18 & 25.7 & 22 & 21.8 & 20 & 31.7 & 97 & 27.2 \\
\hline Tenant & 4 & 3.3 & 6 & 8.6 & 7 & 6.9 & 11 & 17.5 & 28 & 7.9 \\
\hline \multicolumn{11}{|c|}{ Farming experience } \\
\hline
\end{tabular}




\begin{tabular}{lcccccccccc}
\hline Low (Up to 10) & 31 & 25.4 & 22 & 31.4 & 19 & 18.8 & 32 & 50.8 & 104 & 29.2 \\
Medium $(>11-20)$ & 34 & 27.9 & 30 & 42.9 & 33 & 32.7 & 17 & 27.0 & 114 & 32.0 \\
$>20$ & 57 & 46.7 & 18 & 25.7 & 49 & 48.5 & 14 & 22.2 & 138 & 38.8 \\
\hline & \multicolumn{10}{c}{ Income sources } \\
\hline Farming only & 47 & 38.5 & 56 & 80.0 & 69 & 68.3 & 47 & 74.6 & 219 & 61.5 \\
Farming + non-farming & 75 & 61.5 & 14 & 20 & 32 & 31.7 & 16 & 25.4 & 137 & 38.5 \\
\hline
\end{tabular}

Table 1 shows, $29.2 \%$ of the respondents were young followed by the $41 \%$ of respondents who were in their middle of the ages. Almost $30 \%$ of respondents were old. Table 2 further shows that $22.2 \%$ were illiterate and $77.8 \%$ of farmers had formal education. Among the participating farmers, $38.5 \%$ had an educational level of primary to middle and one fourth (25\%) of respondents were qualified to matric level. Of the total respondents, $13.5 \%$ had a qualification level of more than matriculation.

Table 2 further indicates that $36.8 \%$ of the respondents had less than 5 members in their households. Almost $39 \%$ of respondents had 6-10 family members. One fourth $(24.4 \%)$ of the households had more than 10 family members. The majority of respondents (64.9\%) were owners of their lands. Greater than one fourth (27.2\%) of respondents were owner-cum-tenants and $7.9 \%$ of respondents were tenants. This implies that owners outnumber the owner-cum-tenants and tenant farmers in the study area. Out of total respondents, $29.2 \%$ (219 farmers) had the farming experience of under 10 years. Very close to one-third of respondents (32\%) had the experience of farming between 11 to 20 years while $38.8 \%$ (138 farmers) were the highly experienced with an experience surpassing over two decades. For $61.6 \%$ of respondents, farming was the sole and key income sources. Of the total respondents, $38.5 \%$ of respondents had an emphasis on multiple income sources to generate income for their sustainable livelihoods. Income source had a statistically insignificant difference regarding the adoption of weed management techniques under different cropping systems.

\section{Factors affecting the awareness level among farmers regarding weed management practices}

This section of the study explores the contribution of different factors in impeding the awareness level of farmers regarding weeds management practices. The considerable factors likely to impact were, lack of knowledge, conservativeness, lack of interest, lack of motivation, lack of resources and poor exposure to the different information sources. The response of the farmers was recorded on five-point Likert scale such as, 1-very low, 2-low, 3=medium, 4=high, 5=very high and mean values were calculated in order to unveil the impact of different factors on awareness level. The detailed description is given in Table 2.

Table 2. Factors affecting awareness level of respondents about weed management practices under different cropping systems

\begin{tabular}{lcccccccc}
\hline Factors & \multicolumn{2}{c}{ R-W } & \multicolumn{2}{c}{ R-P } & \multicolumn{2}{c}{ R-M } & \multicolumn{2}{c}{ R-Peas } \\
\cline { 2 - 8 } & Mean & Rank & Mean & Rank & Mean & Rank & Mean & Rank \\
\hline Lack of knowledge & $3.30 \pm 1.25$ & 2 & $3.46 \pm 1.25$ & 1 & $3.67 \pm 1.25$ & 1 & $3.27 \pm 1.23$ & 2 \\
Conservative behaviour & $2.86 \pm 1.20$ & 6 & $3.14 \pm 1.28$ & 6 & $3.17 \pm 1.26$ & 5 & $3.11 \pm 1.25$ & 5 \\
Lack of interest & $3.15 \pm 1.23$ & 3 & $3.43 \pm 1.23$ & 2 & $3.30 \pm 1.33$ & 4 & $2.89 \pm 1.26$ & 6 \\
Lack of motivation & $3.01 \pm 1.29$ & 4 & $3.36 \pm 1.26$ & 4 & $3.15 \pm 1.22$ & 6 & $3.22 \pm 1.30$ & 3 \\
Lack of resources & $3.40 \pm 1.25$ & 1 & $3.17 \pm 1.23$ & 5 & $3.47 \pm 1.28$ & 3 & $3.16 \pm 1.26$ & 4 \\
Less exposure to information & $2.98 \pm 1.22$ & 5 & $3.39 \pm 1.12$ & 3 & $3.57 \pm 1.27$ & 2 & $3.51 \pm 1.28$ & 1 \\
sources & & & & & & & & \\
\hline
\end{tabular}

Table 2 indicates that in R-W cropping system, lack of resources was the leading factors hampering the awareness about the weed management practices $(\bar{x}$
$=3.40$, Rank 1). Lack of knowledge and lack of interest of farmers in farming were $2^{\text {nd }}$ and $3^{\text {rd }}$ leading factors with obtained mean value of 3.30 and 3.15 respectively. Lack 
of motivation and lack of exposure to information sources were ranked $4^{\text {th }}$ and $5^{\text {th }}$, respectively.

In R-P cropping system, lack of knowledge was the foremost of the various factors $(\bar{x}=3.46)$ followed by lack of interest ( $\bar{x}=3.43$, Rank 2 ) and lack of exposure to information sources $(\bar{x}=3.39)$. Lack of motivation $(\bar{x}$ $=3.36)$ and lack of resources $(\bar{x}=3.17)$ were the $4^{\text {th }}$ and $5^{\text {th }}$ ranked impeding factors. The mean values for all the five factors remained more than 3 indicating the impeding level of more than medium extent.

In R-M cropping system, lack of knowledge was ranked $1^{\text {st }}$ in terms of impeding the awareness about the weed management practices among farmers $(\bar{x}=3.67)$. The impact of having no knowledge was close to high level. Lack of exposure to information sources obtained mean value of 3.57 and ranked $2^{\text {nd }}$ on the five-point Likert scale. Lack of resources and lack of interest and conservative behavior of respondents were $3^{\text {rd }}, 4^{\text {th }}$ and $5^{\text {th }}$ leading factors impeding the awareness level.

In R-Peas cropping system, lack of exposure to information sources was perceived foremost by the farmers regarding impeding the awareness among farmers $(\bar{x}=3.51)$. Lack of knowledge stood on $2^{\text {nd }}$ rank with mean value of 3.27 . This indicates that the impact of lack of knowledge was of greater than medium level. Lack of resources, lack of motivation and conservative behaviour were ranked $3^{\text {rd }}, 4^{\text {th }}$ and $5^{\text {th }}$ leading factor impeding the awareness about the weed management practices among farmers.

\section{Factors affecting adoption of weed management practices}

This section portrays the impact of different factors on the adoption of recommended weed management practices such as (i) preventive control methods (ii) cultural and ecological control methods (iii) manual control methods (iv) mechanical control methods and (v) chemical control methods. The response was recorded on five-point Likert scale 1=very low 2=low 3 =medium 4=high 5-very high and mean values were calculated to explore the impact. The data in this regard are given in Table 3.

Table 3. Factors affecting adoption level of respondents about weed management practices under different cropping systems.

\begin{tabular}{|c|c|c|c|c|c|c|c|c|}
\hline \multirow[t]{2}{*}{ Factors } & \multicolumn{2}{|c|}{ R-W } & \multicolumn{2}{|l|}{ R-P } & \multicolumn{2}{|c|}{ R-M } & \multicolumn{2}{|c|}{ R-Peas } \\
\hline & Mean & Rank & Mean & Rank & Mean & Rank & Mean & Rank \\
\hline \multicolumn{9}{|c|}{ Preventive control methods } \\
\hline $\begin{array}{l}\text { Shortage of labour for cleaning } \\
\text { water channels }\end{array}$ & $3.51 \pm 1.35$ & 6 & $3.40 \pm 1.34$ & 8 & $3.23 \pm 1.31$ & 9 & $3.35 \pm 1.37$ & 17 \\
\hline $\begin{array}{l}\text { Lack of awareness for cleaning } \\
\text { tools and machinery }\end{array}$ & $2.78 \pm 1.15$ & 18 & $2.96 \pm 1.36$ & 10 & $3.10 \pm 1.29$ & 14 & $2.95 \pm 1.44$ & 14 \\
\hline Labour over charges & $2.74 \pm 1.14$ & 20 & $3.10 \pm 1.38$ & 9 & $3.13 \pm 1.32$ & 12 & $3.08 \pm 1.45$ & 16 \\
\hline \multicolumn{9}{|c|}{ Cultural and ecological control methods } \\
\hline $\begin{array}{l}\text { Lack of knowledge about inter } \\
\text { cropping }\end{array}$ & $3.72 \pm 1.25$ & 4 & $3.50 \pm 1.33$ & 6 & $3.38 \pm 1.33$ & 7 & $3.52 \pm 1.38$ & 19 \\
\hline $\begin{array}{l}\text { Lack of knowledge about } \\
\text { mulching }\end{array}$ & $3.60 \pm 1.28$ & 5 & $2.84 \pm 1.29$ & 14 & $3.17 \pm 1.32$ & 11 & $2.84 \pm 1.35$ & 11 \\
\hline $\begin{array}{l}\text { Lack of knowledge about crop } \\
\text { rotation }\end{array}$ & $2.70 \pm 1.10$ & 21 & $2.93 \pm 1.30$ & 11 & $2.91 \pm 1.32$ & 15 & $2.95 \pm 1.39$ & 13 \\
\hline $\begin{array}{l}\text { Not ready to take risk on sole } \\
\text { crop }\end{array}$ & $2.70 \pm 1.14$ & 22 & $3.83 \pm 1.27$ & 2 & $3.87 \pm 1.21$ & 2 & $3.70 \pm 1.26$ & 22 \\
\hline Lack of technology & $2.57 \pm 1.11$ & 23 & $2.90 \pm 1.27$ & 13 & $2.89 \pm 1.30$ & 17 & $2.90 \pm 1.33$ & 12 \\
\hline \multicolumn{9}{|c|}{ Manual control methods } \\
\hline Time consuming & $2.53 \pm 1.12$ & 24 & $2.56 \pm 1.09$ & 17 & $2.44 \pm 1.20$ & 24 & $2.51 \pm 1.15$ & 8 \\
\hline High labor cost & $3.43 \pm 1.35$ & 7 & $2.80 \pm 1.28$ & 15 & $3.11 \pm 1.26$ & 13 & $2.78 \pm 1.35$ & 10 \\
\hline Non-availability of labour & $3.27 \pm 1.32$ & 8 & $2.74 \pm 1.23$ & 16 & $2.91 \pm 1.77$ & 16 & $2.68 \pm 1.32$ & 9 \\
\hline
\end{tabular}




\begin{tabular}{|c|c|c|c|c|c|c|c|c|}
\hline $\begin{array}{l}\text { Lack of technical skills regarding } \\
\text { mechanical weed control } \\
\text { measures }\end{array}$ & $3.16 \pm 1.36$ & 9 & $2.93 \pm 1.30$ & 12 & $3.19 \pm 1.38$ & 10 & $3.02 \pm 1.30$ & 15 \\
\hline Unavailability of farm machinery & $2.78 \pm 1.15$ & 19 & $2.26 \pm 1.07$ & 24 & $2.70 \pm 1.24$ & 21 & $2.19 \pm 1.10$ & 1 \\
\hline \multicolumn{9}{|c|}{ Chemical control methods } \\
\hline $\begin{array}{l}\text { Lack of knowledge for selection of } \\
\text { appropriate } \\
\text { weedicides/herbicides }\end{array}$ & $3.08 \pm 1.34$ & 10 & $3.70 \pm 1.28$ & 4 & $3.64 \pm 1.33$ & 4 & $3.60 \pm 1.31$ & 21 \\
\hline $\begin{array}{l}\text { Lack of knowledge about proper } \\
\text { time of spraying }\end{array}$ & $3.04 \pm 1.27$ & 11 & $3.60 \pm 1.32$ & 5 & $3.56 \pm 1.34$ & 5 & $3.52 \pm 1.38$ & 20 \\
\hline $\begin{array}{l}\text { Inadequate knowledge about } \\
\text { proper use of spray machine }\end{array}$ & $2.89 \pm 1.22$ & 14 & $2.56 \pm 1.09$ & 18 & $2.82 \pm 1.32$ & 18 & $2.49 \pm 1.16$ & 7 \\
\hline $\begin{array}{l}\text { Lack of knowledge about spraying } \\
\text { methods }\end{array}$ & $2.92 \pm 1.25$ & 13 & $2.40 \pm 1.06$ & 21 & $2.72 \pm 1.25$ & 20 & $2.35 \pm 1.11$ & 4 \\
\hline $\begin{array}{l}\text { Lack of knowledge about } \\
\text { calculated dose of weedicides/ } \\
\text { herbicides }\end{array}$ & $3.01 \pm 1.17$ & 12 & $2.51 \pm 1.11$ & 19 & $2.80 \pm 1.19$ & 19 & $2.46 \pm 1.16$ & 6 \\
\hline $\begin{array}{l}\text { Unaware about the use of } \\
\text { herbicide nozzles }\end{array}$ & $2.81 \pm 1.15$ & 17 & $2.29 \pm 1.07$ & 23 & $2.59 \pm 1.14$ & 23 & $2.19 \pm 1.09$ & 2 \\
\hline $\begin{array}{l}\text { Inadequate knowledge about } \\
\text { spraying height }\end{array}$ & $2.85 \pm 1.16$ & 15 & $2.34 \pm 1.04$ & 22 & $2.63 \pm 1.12$ & 22 & $2.19 \pm 1.07$ & 3 \\
\hline $\begin{array}{l}\text { High } \quad \text { cost } \\
\text { weedicides/herbicides }\end{array}$ & $3.84 \pm 1.23$ & 3 & $2.50 \pm 1.08$ & 20 & $3.37 \pm 1.32$ & 8 & $2.44 \pm 1.13$ & 5 \\
\hline $\begin{array}{l}\text { Adulteration } \\
\text { weedicides/herbicides }\end{array}$ & $2.84 \pm 1.18$ & 16 & $3.50 \pm 1.31$ & 7 & $3.51 \pm 1.36$ & 6 & $3.51 \pm 1.33$ & 18 \\
\hline Shortage of capital/finance & $4.10 \pm 1.13$ & 1 & $3.84 \pm 1.17$ & 1 & $4.08 \pm 1.13$ & 1 & $3.86 \pm 1.78$ & 24 \\
\hline High cost of diesel & $4.04 \pm 1.18$ & 2 & $3.81 \pm 1.21$ & 3 & $3.84 \pm 1.21$ & 3 & $3.79 \pm 1.28$ & 23 \\
\hline
\end{tabular}

Table 3 indicates that in $\mathrm{R}-\mathrm{W}$ cropping system, shortage of finance ( $\overline{\mathrm{x}}=4.30$, Rank 1$)$, high cost of diesel $(\overline{\mathrm{x}}=4.04$, Rank 2), high cost of weedicides/herbicides $(\bar{x}=3.84$, Rank 3), lack of knowledge about the intercropping ( $\bar{x}$ =3.72, Rank 4) and lack of knowledge about the mulching ( $\bar{x}=3.60$, Rank 5) were the prominent factors affecting the adoption of weed management practices among farmers. This implies that due to inadequate finance the farmers were not able to adopt some of weed management techniques. Pertaining to finance shortage farmers were unlikely to irrigate their fields with tube well which takes a lot of diesel expenses. Farmers were not known to intercropping, nevertheless the intercropping if adopted carefully could have lower the infestation of weeds.

In R-P cropping system, shortage of capital/finance was the 1st ranked factor impeding the adoption of weed management among farmers $(\overline{\mathrm{x}}=3.84)$. Finance had tremendous role in fostering the adoption of innovations. When the farmers have financial shortage the adoption process can get slower. The financial instability does not allow farmers to take risks, instead they prefer conventional approaches. Farmers were not ready to take risk on sole crop was identified as $2^{\text {nd }}$ leading factor $(\bar{x}=3.83)$ affecting the adoption of weeds management techniques. High costs of inputs were ranked $3^{\text {rd }}(\bar{x}=3.81)$ in terms of effecting the adoption of weed management practices.

High costs of inputs not only increase the production cost of the farmers but also decreases their financial position. The financial instability could impact the decision making of farmers regarding adoption of technologies. Lack of knowledge for selection of appropriate weedicides/herbicides and lack of knowledge about proper time of spraying were identified as $4^{\text {th }}$ and $5^{\text {th }}$ ranked factors with mean values of 3.70 and 3.63, respectively. It is well addressed that inadequate awareness and knowledge had significant influence over the decisions regarding adoption of technologies. 
Farmers in R-M cropping system perceived shortage of capital/finance as a leading factor ( $\overline{\mathrm{x}}=4.08$, Rank 1) hindering the adoption of weed management techniques among farmers. Not ready to take risk on sole crop was rated $2 \mathrm{nd}(\overline{\mathrm{x}}=3.87)$ by the farmers. Finance has great dealing with the taking risks in agriculture. Financial weak farmers are found reluctant to take risks and follow the conventional mode of farming in line to their resources. High cost of diesel was ranked $3^{\text {rd }}(\bar{x}=3.84)$ in terms hampering the adoption of weed management techniques. Farmers further perceived that, lack of knowledge for the selection of appropriate weedicides/herbicides was one of the key factors affecting the adoption of right weedicides $(\bar{x}=3.64$, Rank 4). Due to poor knowledge and awareness farmers were using conventional techniques to cater the weeds and using traditional weedicides which have lower impact on weeds control. The adoption was further obstacle by the lack of knowledge about proper use of spray machines by the farmers ( $\bar{x}=3.56$, Rank 5 ).

In R-peas cropping system, shortage of finance appeared as leading factor affecting the adoption of weeds management techniques ( $\bar{x}=3.86$, Rank 1$)$. The intensity of hindrances was very closer to high level. High cost of diesel was perceived as $2^{\text {nd }}$ leading factor with mean value of 3.79. Not ready to take risk on sole crop, Lack of knowledge for selection of appropriate weedicides/herbicides and lack of knowledge about proper time of spraying were $3^{\text {rd }}, 4^{\text {th }}$ and $5^{\text {th }}$ leading factors hindering the adoption level with obtained mean value of $3.70,3.60$ and 3.52 respectively.

If we summarize the factors affecting farmers awareness and adoption across the four cropping systems, few of the factors stood key, as they were found affecting the farmers across the study area. For instance, shortage of finance, high inputs cost, high cost of diesel and inadequate knowledge were the mutual and key factors affecting the adoption among farmers. Number of research studies such as Hassan et al. (2002); Nlerum (2008); Siddiqui et al. (2006); Nzomoi et al. (2007); Yasin (2015) and Ashraf et al. (2015) have reported the significant association between the adoption of technologies and socio-economic characteristics of the respondents. These studies incur that economically weak farmers had less chances to adopt the particular technologies. Few more studies such as Ashraf (2001); Siddiqui et al. (2006); Salehin et al. (2009) had reported that awareness among the farmers about the technologies was related with the socio-economic attributes of the farmers such as age, education, income and size of land holding. Inadequate awareness refers to the inadequate knowledge among farmers pertinent to poor socio-economic attributes the farmers had poor level of knowledge. This poor knowledge among farmers restricts adoption of technologies. Ayoade and Akintonde (2012) have reported that the constraints faced by the farmers significantly limit the adoption of technologies.

\section{CONCLUSION AND RECOMMENDATION}

This study concludes that weeds are indispensable to be pulled out but there were number of factors across tin he four cropping systems that were hampering the awareness level and adoption of specific technologies deemed necessary for the effective management. Of the various factors, inadequate resources, inadequate knowledge and limited exposure to the information sources were the key factors affecting the awareness level across four cropping system, Rice-Wheat, RiceMaize, Rice-potato and Rice-Peas. This limited awareness obstacle the adoption of recommended weeds management techniques. As for as adoption was concerned, shortage of finance, high inputs cost, high cost of diesel and inadequate knowledge were most prominent among farmers in four cropping systems. These factors do have closely associated with the socioeconomic conditions of the farmers. This implies, until the socio-economic conditions of the farmers are not improved the adoption of the weed management techniques cannot be improved.

This study recommends that in order to create awareness and foster the adoption of weed management technologies, the EFS should possess latest knowledge and introduce environment friendly techniques among farmers to control weeds. This latest knowledge should be passed on to the farmers with diversified approaches such as integration of Information Communication Technologies in dissemination of information could happen as effective.

The public and private sector should collaborate with public sector in order to facilitate their farmers. The public-private partnership in agriculture especially for weed management could be effective for the farmers. It is recommended that EFS of public sector in order to utilize the potential of modern gadgets like mobile, helpline, apps such as What Sapp etc. The TV and Radio 
are needed to be revamped. Broadcasting agriculture related programs on TV and Radio can attract the farmers.

\section{REFERENCES}

Ashraf, I. 2001. A study into the effectiveness of communication methods used by pesticide companies to popularize their products among the farmers of tehsil arifwala. Univ. of Agri, Faisalabad., University of Agriculture Faisalabad.

Ashraf, S., G. A. Khan, S. Ali and M. Iftikhar. 2015. Socioeconomic determinants of the awareness and adoption of citrus production practices in Pakistan. Ciência Rural, 45: 1701-06.

Ayoade, A. and J. Akintonde. 2012. Constraints to adoption of agricultural innovations among women farmers in Isokan Local Government Area, Osun State. International Journal of Humanities and Social Science, 2: 57-61.

Borlaug, N. E. 2002. The green revolution revisited and the road ahead Nobelprize. org Stockholm, Sweden.

Cartmell, D., C. L. Orr and D. B. Kelemen. 2004. Methods of information dissemination to limited-scale land owners. Oklahoma State University.

Chamanabad, H. R. M. 2011. Effect of nitrogen rates on critical period for weed control in potato. Pakistan Journal of Weed Science Research, 17.

Chauhan, B. S. 2012. Weed Ecology and Weed Management Strategies for Dry-Seeded Rice in Asia. Weed Technology, 26: 1-13.

Chauhan, B. S. and J. Opeña. 2013. Implications of plant geometry and weed control options in designing a low-seeding seed-drill for dry-seeded rice systems. Field Crops Research, 144: 225-31.

Cook, R. J. 1988. Biological control and holistic planthealth care in agriculture. American Journal of Alternative Agriculture, 3: 51-62.

Fadare, O. A., D. Akerele and B. Toritseju. 2014. Factors influencing adoption decisions of maize farmers in Nigeria. International Journal of Food and Agricultural Economics (IJFAEC), 2: 45-54.

Hassan, M. Z. Y., B. N. Siddiqui and M. N. Irshad. 2002. Effect of socio-economic aspects of mango growers on the adoption of recommended horticultural practices. Pakistan Journal of Agricultural Sciences, 39: 20-21.
Jabran, K. and B. S. Chauhan. 2015. Weed management in aerobic rice systems. Crop Protection, 78: 15163.

Kropff and Walter. 2000. EWRS and the challenges for weed research at the start of a new millennium. Weed Research, 40: 7-10.

Maqbool, M., A. Tanveer, Z. Ata and R. Ahmad. 2006. Growth and yield of maize (Zea mays L.) as affected by row spacing and weed competition durations. Pakistan Journal of Botany, 38: 1227.

Muller, S., Scheepens and Greaves. 2000. Biological control of weeds in European crops: recent achievements and future work. Weed Research, 40: 83-98.

Nlerum, F. E. 2008. Socio-Economic Characteristics As Correlates Of Adoption Among Yam Farmers In Rural Ikwerre Areas of Rivers State, Nigeria. Global Approaches to Extension Practice: A Journal of Agricultural Extension, 2.

Norsworthy, J. K., S. M. Ward, D. R. Shaw, R. S. Llewellyn, R. L. Nichols, T. M. Webster, K. W. Bradley, G. Frisvold, S. B. Powles, N. R. Burgos, W. W. Witt and M. Barrett. 2012. Reducing the Risks of Herbicide Resistance: Best Management Practices and Recommendations. Weed Science, 60: 31-62.

Nzomoi, J., J. Byaruhanga, H. Maritim and P. Omboto. 2007. Determinants of technology adoption in the production of horticultural export produce in Kenya. AFRICAN JOURNAL OF BUSINESS MANAGEMENT, 1: 129-35.

Oad, F., M. Siddiqui and U. Buriro. 2007. Growth and yield losses in wheat due to different weed densities. Asian journal of plant sciences, 6: 17376.

Oerke, E. C. 2005. Crop losses to pests. The Journal of Agricultural Science, 144: 31-43.

Prudent, P., S. Loko, D. Deybe and M. Vaissayre. 2007. Factors limiting the adoption of IPM practices by cotton farmers in Benin: a participatory approach. Experimental Agriculture, 43: 113-24.

Rao, A. N., S. P. Wani, M. Ramesha and J. K. Ladha. 2015. Weeds and Weed Management of Rice in Karnataka State, India. Weed Technology, 29: 117.

Riaz, M., M. A. Malik, T. Z. Mahmood and M. Jamil. 2006. Effect of various weed control methods on yield and yield components of wheat under different 
cropping patterns. International Journal of Agriculture and Biology, 8: 636-40.

Rubiales, D., J. Verkleij, M. Vurro, A. J. Murdoch and D. M. Joel. 2009. Parasitic plant management in sustainable agriculture. Weed Research, 49: 1-5.

Salehin, M. M., M. S. Kabir, K. M. Morshed and K. S. Farid. 2009. Socioeconomic changes of farmers due to adoption of rice production technologies in selected areas of Sherpur district. Journal of the Bangladesh Agricultural University, 7: 335-41.

Siddiqui, B. N., S. Muhammad and N. H. Malik. 2006. Effect of socio-economic aspects on the awareness and adoption of recommended horticultural practices by apple growers in Baluchistan, Pakistan. Pakistan Journal of Agricultural Sciences, 43: 1-2.
Smith, R. G., L. W. Atwood, F. W. Pollnac and N. D. Warren. 2015. Cover-Crop Species as Distinct Biotic Filters in Weed Community Assembly. Weed Science, 63: 282-95.

Vencill, W. K., R. L. Nichols, T. M. Webster, J. K. Soteres, C. Mallory-Smith, N. R. Burgos, W. G. Johnson and M. R. McClelland. 2012. Herbicide Resistance: Toward an Understanding of Resistance Development and the Impact of HerbicideResistant Crops. Weed Science, 60: 2-30.

Yasin, M. 2015. Analysis of adoption gap of weed management practices among farmers under different cropping systems in district khanewal (Punjab), Pakistan, Univ. of Agric., Faisalabad., University of Agriculture Faisalabad. 